\title{
Mortality in parents following the death of a child: a nationwide follow-up study from Sweden
}

\section{Citation}

Rostila, Mikael, Jan Saarela, and Ichiro Kawachi. 2011. "Mortality in Parents Following the Death of a Child: A Nationwide Follow-up Study from Sweden." Journal of Epidemiology and Community Health 66 (10): 927-33. https://doi.org/10.1136/jech-2011-200339.

\section{Permanent link}

http://nrs.harvard.edu/urn-3:HUL.InstRepos:41275600

\section{Terms of Use}

This article was downloaded from Harvard University's DASH repository, WARNING: This file should NOT have been available for downloading from Harvard University's DASH repository.

\section{Share Your Story}

The Harvard community has made this article openly available.

Please share how this access benefits you. Submit a story.

\section{Accessibility}




\title{
Mortality in parents following the death of a child: a nationwide follow-up study from Sweden
}

\author{
Mikael Rostila, ${ }^{1}$ Jan Saarela, ${ }^{2}$ Ichiro Kawachi ${ }^{3}$
}

${ }^{1}$ Centre for Health Equity Studies, Stockholm University, Stockholm, Sweden

${ }^{2}$ Ábo Akademi University, Vasa, Finland

${ }^{3}$ Harvard School of Public Health, Boston, Massachusetts, USA

\section{Correspondence to}

Dr Mikael Rostila, Centre for Health Equity Studies (CHESS), Stockholm University/Karolinska Institutet, Sveavägen 160, SE-106 91 Stockholm, Sweden; mikael.rostila@chess.su.se

Accepted 12 October 2011 Published Online First

1 November 2011

\begin{abstract}
Background The death of a young child is so devastating that it can increase the risk of mortality in the grieving parent. Little is known about the impact of an adult child's death on the health of parents.

Methods The authors conducted a follow-up study between 1980 and 2002 based on a linked-registers database that contains the total Swedish population. The authors examined mortality from all causes, natural causes and unnatural causes among parents following the death of children aged 10-49 years.

Results An increased mortality risk (RR $1.31,95 \% \mathrm{Cl}$ 1.02 to 1.68 ) in mothers following the death of a minor child (10-17 years) was found and especially following unnatural deaths (primarily accidents and suicides). Mothers also experienced elevated mortality following the death of an adult child aged 18-25 years (RR 1.15, 95\% Cl 1.03 to 1.29). Bereavement effects among fathers were more attenuated and chiefly found after $>8$ years of follow-up. From a short-term perspective (1-3 years), the death of an adult child ( $>25$ years) was somewhat protective for parents. However, over longer follow-up periods, it approached (4-8 years) and exceeded (>8 years) the death risk of the general population. Conclusions These findings corroborate and extend earlier findings suggesting elevated mortality risks also following the death of an adult child.
\end{abstract}

\section{INTRODUCTION}

In economically advanced societies, the death of parents precedes the death of children in the normative life cycle. Hence, the death of a child before their parents is considered one of the most stressful and traumatic life events a person may encounter. ${ }^{1}{ }^{2}$ Studies suggest that parents suffer more intense grief after the death of a child compared with the bereavement following the death of either a spouse or a parent. ${ }^{3-5}$ In turn, bereavement is thought to adversely affect health through both acute psychophysiological mechanisms (eg, the phenomenon of 'takotsubo' cardiomyopathy or 'broken heart syndrome'), which has been observed to follow episodes of intense psychogenic shock, ${ }^{2} 67$ as well as through longer term mechanisms involving changes in health-related behaviours such as smoking, increased alcohol consumption, and poor diet and exercise habits. ${ }^{89}$

Most empirical research linking the death of a child to the health of parents suggests adverse health effects. Studies have found that the death of a young child increases parental mortality from all causes, ${ }^{2}$ as well as the risk of depressive symptoms, ${ }^{10}$ certain types of cancer, ${ }^{11}$ myocardial infarction, ${ }^{12}$ poor self-rated health, ${ }^{13}$ diabetes ${ }^{14}$ and suicide. ${ }^{15}$ Yet, some analyses have found no increase in risk in parents with regard to general health status, ${ }^{16}$ cancer morbidity ${ }^{17}$ or stroke. ${ }^{18}$ Studies have also examined the duration of bereavement. Some research that has examined longer term consequences following child deaths has found that grief persists for the remainder of the parent's life, ${ }^{19-21}$ while others show evidence for shorter term consequences. ${ }^{22-24}$

An important threat to causal inference in these studies is the possibility that both the death of a child as well as the subsequent ill health of the parent share a common prior cause, that is, there is confounding of the relationship by an unobserved third variable. For example, if a child dies of a chronic disease with a strong genetic component (eg, heart attack caused by hyperlipidaemia), this may be a marker of biological resemblance between the child and the parent that may increase the parents' risk of ill health. One approach to getting a step closer to causal inference is to examine the death of the child according to specific causes. The death of a child due to unexpected, sudden or unforeseen circumstances, such as homicides and accidents (as compared with deaths due to chronic diseases), may assist in teasing out causation from confounding.

Previous research has chiefly examined parental health effects caused by the loss of a minor (young) child. Relatively little is known about the impact of older children's death on parental mortality, although two studies found limited support for increased mortality and cancer incidence, respectively, among the parents of accident victims and war casualties (ie, children who died from unnatural causes). ${ }^{25} 26$ Since the parent-child attachment weakens as the child grows older, ${ }^{27}$ one might expect that the effect of an older child's death on the parental mortality risk is lower than that of a younger child's death. Parent's responses to the loss may also vary by the age of the child (eg, because of variation in the importance of psychophysiological mechanisms vs changes of health behaviours).

Our aim is to complement and extend the literature on parental bereavement by studying parents' mortality risk subsequent to the death of both minor and adult children, using intergenerational linked data from nationwide Swedish registers. We postulate that the effect of a child's death will depend on the age of the child at the time of death, the time interval since the death, parent's sex and the nature of the child's death (natural or unnatural cause). The design of our analyses is similar to that of a previous study that focused on the effect of a minor child's death. ${ }^{2}$ Our study is not confined to 
young children; we are able to extend our observations to adult children because of our ability to link each individual to his or her registered mother and father across multiple generations.

\section{DATA AND METHODS}

We conducted a follow-up study based on data from the Swedish Work and Mortality Database (HSIA) maintained and handled by the Centre for Health Equity Studies in Stockholm. HSIA is a multiple-linked database of national Swedish routine registers, covering all individuals who lived in Sweden at the end of 1980 and were born before 1986. Each person is linked to the mother and the father and can be observed until the end of 2002. The data were approved by the Regional Ethical Review board of Karolinska Institutet in 2002-11-11 (decision no. 02-481). The ethical approval provides directions for using the data (eg, all data should be anonymous, how data should be stored, how it should be handled by researchers etc). All these regulations were followed by the authors. We further restricted the data to people born in Sweden, who also had parents born in Sweden as there are large information gaps on the links between immigrated parents and their children. For all persons who died during the period 1981-1998, we recorded the month of death and main cause of death. These children were stratified into five different groups consisting of mothers and fathers with offspring aged 10-17 years (born 1970-1980), 18-25 years (born 1962-1972), 26-33 years (born 1954-1964), 34-41 years (born 1946-1956) and 42-49 years (born 1938-1948). All parents who were alive at the time of a child's death constituted our 'exposed families'. They were subsequently followed with regard to their own month of death. All parents could be followed for at least 4 years after the death of a child. The longest potential follow-up period was 22 years. The comparison group of 'unexposed families' comprises a $5 \%$ random sample of parents with children born during the same years but whose children survived the entire observation period.

We estimated 1-year mortality risks (ie, the risk of dying as measured at the 1-year level) for mothers and fathers using Cox regressions with appropriate weights. These weights were included in order to balance the data according to the sampling proportion of the 'unexposed families'. Our primary aim was to see how the death of a child influences subsequent mortality in parents. Hence, we calculated mortality risk ratios (with $95 \%$ CIs based on corrected $t$ statistics) comparing exposed families to unexposed families. We adjusted for a number of potential confounders including parental age, socioeconomic status, marital status and number of children. We also controlled for whether the parents lived in close geographic proximity to the offspring, as well as whether they lived in large cities. All were measured at the end of 1980, which was before any child death had occurred.

First, we examined the impact of a child's death from all causes on parental mortality. Natural child deaths and unnatural child deaths were separated. Natural causes refer to ICD8 codes 0000-7969 or ICD10 codes A00-R99. Unnatural causes refer to ICD8 codes 8000-9999 or ICD10 codes V01-Y98. The first category refers to deaths caused by diseases, whereas the other contains external causes of death (predominantly accidents and suicides). Second, we studied mortality risk ratios according to time since the death of a child. All analyses were stratified according to child age group (birth year) and parent's sex.

\section{RESULTS}

The upper panel in table 1 gives the number of exposed mothers and exposed fathers in each child age group, together with the main cause of children's death. Because women generally live longer than men, they are also more likely to end up outliving their children compared with men. The table 1 also provides the number of parental deaths (total $\mathrm{N}=9005$ in mothers and 7833 in fathers) and the total number of person-years (358147 in mothers and 226257 in fathers). The lower panel gives corresponding information for the unexposed mothers and fathers.

Table 2 gives a brief overview of the personal characteristics of exposed and unexposed families. The median age was similar, with parents in the unexposed families being slightly older. On the other characteristics, there were also quite few differences within age groups, but since we for the sake of brevity have collapsed the data presentation, this resemblance cannot be explicitly observed here. Exposed and unexposed families were

Table 1 Number of observations, number of deaths and total risk time in exposed and unexposed families by child age group

\begin{tabular}{|c|c|c|c|c|c|}
\hline & $\begin{array}{l}\text { Families with children } \\
\text { aged } 10-17 \text { years } \\
\text { (born } 1970-1980 \text { ) }\end{array}$ & $\begin{array}{l}\text { Families with children } \\
\text { aged } 18-25 \text { years } \\
\text { (born } 1962-1972 \text { ) }\end{array}$ & $\begin{array}{l}\text { Families with children } \\
\text { aged } 26-33 \text { years } \\
\text { (born } 1954-1964 \text { ) }\end{array}$ & $\begin{array}{l}\text { Families with children } \\
\text { aged } 34-41 \text { years } \\
\text { (born } 1946-1956 \text { ) }\end{array}$ & $\begin{array}{l}\text { Families with children } \\
\text { aged } 42-49 \text { years } \\
\text { (born } 1938-1948 \text { ) }\end{array}$ \\
\hline \multicolumn{6}{|l|}{ Exposed families } \\
\hline \multicolumn{6}{|l|}{ Number of mothers, whose children died } \\
\hline From natural causes & 814 & 1430 & 2317 & 4854 & 8638 \\
\hline From unnatural causes & 983 & 3346 & 2861 & 2949 & 2561 \\
\hline Number of deaths in mothers & 65 & 335 & 746 & 2370 & 5489 \\
\hline Number of person-years in mothers & 23551 & 64709 & 65780 & 93035 & 111072 \\
\hline \multicolumn{6}{|l|}{ Number of fathers, whose children died } \\
\hline From natural causes & 799 & 1332 & 1856 & 3201 & 4203 \\
\hline From unnatural causes & 941 & 3085 & 2242 & 1884 & 1232 \\
\hline Number of deaths in fathers & 118 & 616 & 1055 & 2420 & 3624 \\
\hline Number of person-years in fathers & 22690 & 57680 & 48716 & 52604 & 44567 \\
\hline \multicolumn{6}{|l|}{ Unexposed families } \\
\hline Number of mothers & 49470 & 54710 & 49206 & 50432 & 42661 \\
\hline Number of deaths in mothers & 1433 & 3494 & 7251 & 16572 & 24437 \\
\hline Number of person-years in mothers & 841551 & 906988 & 783903 & 748534 & 519784 \\
\hline Number of fathers & 48310 & 52635 & 45945 & 42348 & 28897 \\
\hline Number of deaths in fathers & 2858 & 7257 & 14100 & 23313 & 22485 \\
\hline Number of person-years in fathers & 811217 & 842756 & 670032 & 530467 & 276168 \\
\hline
\end{tabular}

Natural causes refer to ICD8 codes 0000-7969 or ICD10 codes A00-R99 and unnatural causes to ICD8 codes 8000-9999 or ICD10 codes V01-Y98. 
Table 2 Summary characteristics of exposed and unexposed families by parent's sex

\begin{tabular}{|c|c|c|c|c|}
\hline & \multicolumn{2}{|l|}{ Mothers } & \multicolumn{2}{|l|}{ Fathers } \\
\hline & $\begin{array}{l}\text { Exposed } \\
\text { families }\end{array}$ & $\begin{array}{l}\text { Unexposed } \\
\text { families }\end{array}$ & $\begin{array}{l}\text { Exposed } \\
\text { families }\end{array}$ & $\begin{array}{l}\text { Unexposed } \\
\text { families }\end{array}$ \\
\hline \multicolumn{5}{|c|}{ Median age in years at the end of 1980 , families with children aged } \\
\hline $10-17$ years & 32.0 & 32.0 & 34.0 & 34.0 \\
\hline $18-25$ years & 38.0 & 39.0 & 42.0 & 41.0 \\
\hline $26-33$ years & 47.0 & 48.0 & 50.0 & 51.0 \\
\hline $34-41$ years & 56.0 & 57.0 & 58.0 & 60.0 \\
\hline $42-49$ years & 63.0 & 64.0 & 65.0 & 67.0 \\
\hline Median number of children & 3.0 & 3.0 & 3.0 & 3.0 \\
\hline \multicolumn{5}{|l|}{ Marital status $(\%)$} \\
\hline Married & 68.3 & 76.2 & 81.0 & 82.7 \\
\hline Previously married & 27.7 & 17.7 & 14.5 & 11.2 \\
\hline Never married & 4.0 & 6.1 & 4.5 & 6.1 \\
\hline \multicolumn{5}{|l|}{ Socioeconomic status $(\%)$} \\
\hline Blue-collar worker & 29.4 & 29.3 & 34.2 & 34.2 \\
\hline White-collar worker & 17.8 & 24.7 & 28.4 & 34.5 \\
\hline Self-employed & 4.4 & 5.0 & 11.3 & 12.2 \\
\hline Outside labour market & 48.4 & 41.1 & 26.2 & 19.0 \\
\hline Lives in large city (\%) & 26.0 & 23.7 & 24.0 & 22.9 \\
\hline $\begin{array}{l}\text { Lives in same municipality } \\
\text { as child }(\%)\end{array}$ & 70.6 & 79.2 & 71.3 & 77.8 \\
\hline
\end{tabular}

All information refers to the situation at the end of 1980 . Large city means a municipality with more than 100000 inhabitants.

similar with regard to the number of children and variables related to residence. The proportion of people living in stable unions was slightly lower in the exposed families, and individuals in lower socioeconomic positions were somewhat more likely to experience the death of a child.

The effect of a child's death on parental mortality differed according to the age of the child at the time of death (table 3). In bereaved mothers with children aged 10-17 years, the death of a child was associated with a $31 \%$ increase in the mother's subsequent risk of all-cause mortality (95\% CI 1.02 to 1.68 ). When we turn to examine the potential impact of the death of an adult child, we found that the risk of mortality declined with the age of the child at the time of death. The maternal death risk was $15 \%$ higher if a child had died at age $18-25$ years $(95 \%$ CI 1.03 to 1.29 ), $8 \%$ higher (95\% CI 1.00 to 1.16 ) if the child had died at age $26-33$ years, $2 \%$ higher ( $95 \%$ CI 0.97 to 1.06 ) if the child had died at age $34-41$ years and $6 \%$ lower $(95 \%$ CI 0.91 to $0.97)$ if the child had died at age $42-49$ years. Note, however, that the estimate for mothers whose children had died at age 34-41 years was non-significant. In comparison to mothers, father's mortality was affected to a lesser extent following the death of a child and even experienced a reduction in the mortality risk associated with the death of a child aged over 25 years. The estimated effects of the control variables were stable across alternative model specifications in tables 3 and 4 and generally in the expected directions (results not shown). However, they did not confound the association between child death and parental mortality to any noteworthy degree.

When we examined the impact of child death on parental health according to the cause of death, we found that overall the associations were quite similar comparing 'natural' versus 'unnatural' causes of death. The cause of death in the child was important for specific subgroups of parents, though. Thus, mothers who had children dying from unnatural causes at age $10-17$ years experienced a subsequent $48 \%$ increase $(95 \%$ CI 1.08 to 2.03 ) in their own risk of mortality.

The inverse risk of parental mortality following the death of older children was primarily observed in the first few years after the event (table 4). After 4 years, bereaved parents had generally reached the mortality level of non-bereaved parents, and over even longer follow-up periods, their mortality risk was notably higher. Nine or more years after the death of a child aged 26-33 years, bereaved mothers had a $25 \%$ higher mortality risk ( $95 \%$ CI 1.13 to 1.38 ) compared with non-bereaved mothers. For mothers who lost a child aged 34-41 years, the corresponding number was $19 \%$ higher ( $95 \%$ CI 1.13 to 1.26 ) and for those who lost a child aged $42-49$ years, $7 \%$ higher (95\% CI 1.02 to 1.12 ). A similar trend with respect to time since the child's death was observed among fathers. Duration effects did not differ greatly comparing natural versus unnatural child deaths.

\section{DISCUSSION}

The objective of this study was to complement and extend the literature on parental bereavement by analysing the effects of both minor as well as adult children's death on parental mortality risks. Our data based on the total Swedish population register indicate that the death of a child is associated with an overall increased mortality in parents but that the effect is highly dependent on the child's age, the duration of follow-up and parent's sex.

In highly developed countries, children are expected to outlive their parents. When this natural process is reversed, the death of a young child may contribute to feelings of guilt associated with the inability to fulfil the parental role as 'protector'. Given the unnatural character of the event, the social support system may be unprepared to respond appropriately to the grieving parent's needs, which leave the parent vulnerable to grief responses and adverse health. Parents affected must not only deal with sadness

Table 3 Effect of child's death on parental mortality

\begin{tabular}{|c|c|c|c|c|c|c|c|c|c|c|}
\hline & \multicolumn{2}{|c|}{$\begin{array}{l}\text { Families with children } \\
\text { aged } 10-17 \text { years }\end{array}$} & \multicolumn{2}{|c|}{$\begin{array}{l}\text { Families with children } \\
\text { Aged } 18-25 \text { years }\end{array}$} & \multicolumn{2}{|c|}{$\begin{array}{l}\text { Families with children } \\
\text { aged } 26-33 \text { years }\end{array}$} & \multicolumn{2}{|c|}{$\begin{array}{l}\text { Families with children } \\
\text { aged } 34-41 \text { years }\end{array}$} & \multicolumn{2}{|c|}{$\begin{array}{l}\text { Families with children } \\
\text { aged } 42-49 \text { years }\end{array}$} \\
\hline & RR (95\% Cl) & p Value & RR $(95 \%$ CI) & $\overline{p \text { Value }}$ & RR $(95 \%$ CI) & $\bar{p}$ Value & RR $(95 \% \mathrm{CI})$ & $\overline{p \text { Value }}$ & RR (95\% CI) & p Value \\
\hline \multicolumn{11}{|l|}{ Effect on mothers } \\
\hline All deaths & 1.31 (1.02 to 1.68$)$ & 0.03 & 1.15 (1.03 to 1.29$)$ & 0.01 & $1.08(1.00$ to 1.16$)$ & 0.06 & $1.02(0.97$ to 1.06$)$ & 0.67 & 0.94 (0.91 to 0.97 ) & $<0.01$ \\
\hline Natural deaths & 1.11 (0.74 to 1.64$)$ & 0.04 & 1.21 (0.99 to 1.47 ) & 0.04 & 1.10 (0.99 to 1.23$)$ & 0.15 & $1.00(0.95$ to 1.06$)$ & 0.59 & 0.95 (0.92 to 0.98$)$ & $<0.01$ \\
\hline Unnatural deaths & 1.48 (1.08 to 2.03 ) & & 1.13 (0.99 to 1.29$)$ & & 1.06 (0.96 to 1.17$)$ & & 1.04 (0.97 to 1.11$)$ & & 0.90 (0.85 to 0.95$)$ & \\
\hline \multicolumn{11}{|l|}{ Effect on fathers } \\
\hline Natural deaths & $1.13(0.85$ to 1.49$)$ & 0.46 & 1.02 (0.88 to 1.19 ) & 0.51 & 0.91 (0.83 to 1.00$)$ & 0.01 & 0.95 (0.91 to 1.01 ) & $<0.01$ & 0.91 (0.87 to 0.95$)$ & $<0.01$ \\
\hline Unnatural deaths & 1.13 (0.89 to 1.43 ) & & 1.06 (0.96 to 1.16$)$ & & 0.91 (0.84 to 0.99$)$ & & $0.92(0.86$ to 0.98$)$ & & 0.84 (0.78 to 0.90$)$ & \\
\hline
\end{tabular}

RR is mortality risk ratio (with $95 \% \mathrm{Cl}$ ) between exposed and unexposed families, that is, the ratio of the death risk of parents with a deceased child and the death risk of parents with no deceased child, adjusted for effects of all control variables. The $p$ value refers to the Wald statistic of the entire variable and, hence, indicates whether the set of parameters that captures a child's death provides a statistically significant improvement of the model that estimates the parental mortality risk. 


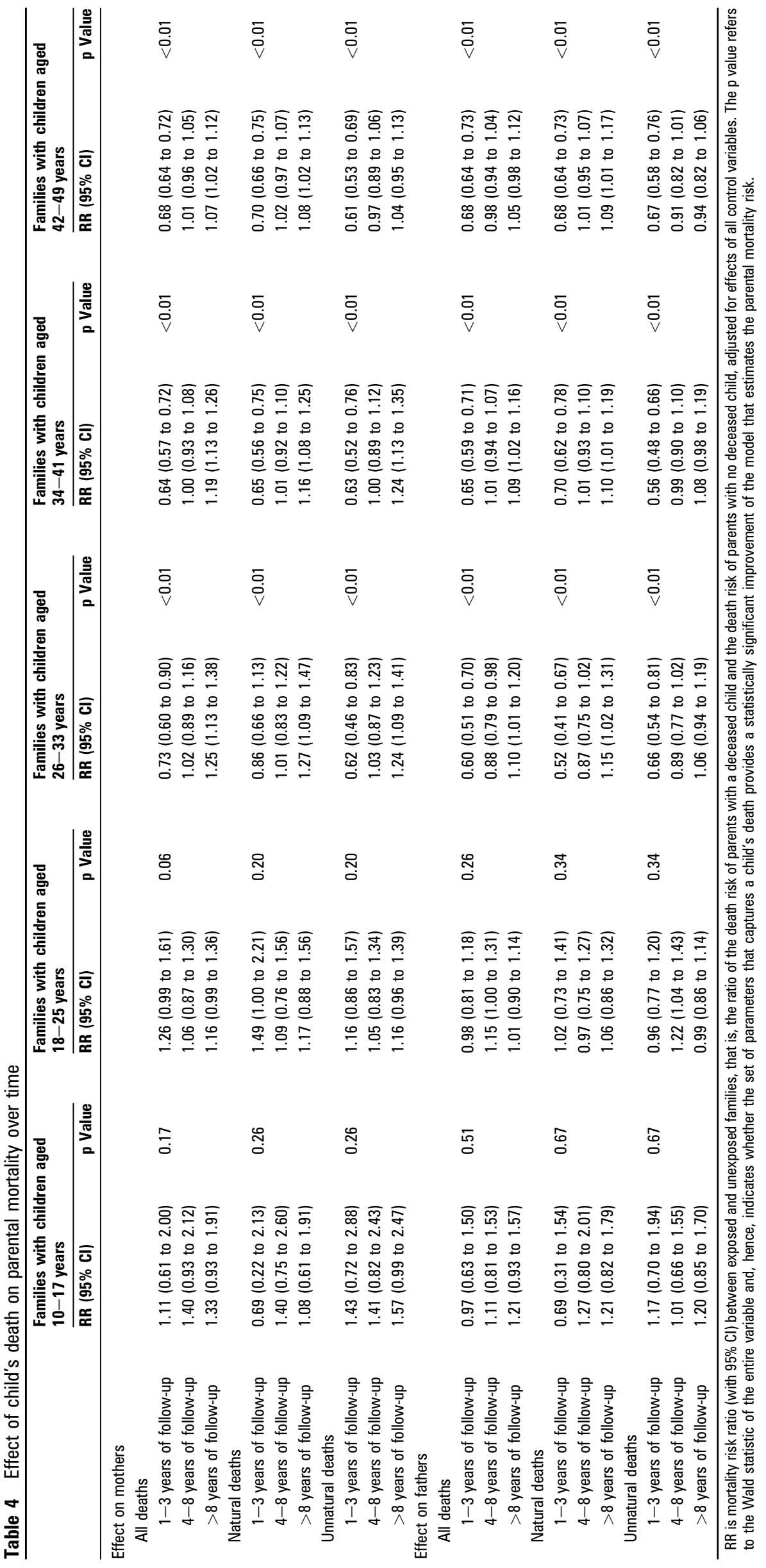


and grief following the loss of a child but also restructured family roles and responsibilities. ${ }^{9} 28$

Our results corroborate previous reports of an excess mortality among parents affected by the death of a minor or young adult child. As there is little expectation of the death of a child at these ages, it may involve high immediate stress levels, strong feelings of grief, great difficulty in accepting the death and few available coping strategies. ${ }^{29} 30$ Our results also suggest that the excess mortality risk following the death of a child is higher for mothers than for fathers, which is in accordance with previous findings. ${ }^{2}$ Throughout the life course norms and role expectations related to gender tend to foster greater attachment of children to mothers than to fathers. ${ }^{31}{ }^{32}$ The mother-child relationship is then characterised by more shared values and attitudes, greater affective closeness and higher stability than the father-child relationship, ${ }^{33} 34$ which may account a stronger adverse impact on mother's mortality risk. Moreover, the fact that more mothers generally have custody of their children when separated or divorced may contribute to mother's greater involvement and higher sensitivity. Yet, generous Swedish parental leave policies fostering greater involvement of fathers in child rearing could contribute to relatively lower mother versus father differentials in mortality compared with countries with less generous policies.

The immediate effect of a child's death is found to taper off with increasing child's age at the time of death. We found that for parents who had lost an older child, mortality risks are even reduced during the first few years, though over the long term, they lie notably above non-bereaved parents' death risks. This finding may indicate that parent's strategies to cope with child deaths vary by the age of the child. It seems likely that the loss of a minor child involves an intense psychogenic shock leading to psychophysiological states as it very strongly conflicts with life cycle expectations. Accordingly, health effects may chiefly occur in a shorter term perspective (1-3 years). However, the acute psychogenic shock might be milder following the death of an adult child as it is a more conceivable event. In its place it may, to a greater extent, contribute to deterioration of health behaviours or severe depression following feelings of emptiness and regret. Given the lifelong affectional relationship between a parent and an adult child, some argue that the loss of a child at these ages could have longer term consequences. ${ }^{19}$ Present findings, however, deviate from a previous study that found limited support for an increased short- or long-term mortality among parents of accident victims and war casualties (eg, unnatural deaths). ${ }^{25}$

Yet, the short-term mortality reduction among parents who experienced the death of an adult child ( $>25$ years) was somewhat surprising, although one study has found a similar pattern regarding the risk of amyotrophic lateral sclerosis. ${ }^{35}$ It could be that children who die from both natural and unnatural causes are over-represented in criminality, drug problems, alcohol abuse or severe depression. Factors that antedate or contribute to the death of an adult child might consequently alleviate negative stressors among recently bereaved parents and contribute to reduced short-term mortality rates. Since many adult children have their own families, their death may also result in stronger bonds between the grieving parent and the family of the deceased child. Increased levels of social support between the parents and the remaining family could contribute to the paradoxical short-term 'beneficial' health effects following the death of an adult child. Additional analyses (results not shown) suggested lower short-term mortality risks among parents whose deceased children had children of their own. Economic resources in the form of bequests (from deceased adult children to their parents) may additionally play some role in buffering against this negative life event in a shorter term perspective. Yet, more research on the causes behind this short-term mortality reduction is suggested.

Our data further indicate that unnatural causes of child death have a stronger impact than natural deaths on parental mortality but mainly among mothers who lost young children (10-17 years). It seems obvious that a major psychogenic shock may follow the unfortunate circumstance of loosing a minor child through an unnatural cause of death (such as an accident, suicide, accident etc), which leads to a severe and complicated grief process. $^{2} 3132$ By and large, however, we did not note substantial differences between the impacts of natural versus unnatural child deaths. These patterns strengthen the possibility that the association between child death and parental health is causal. If the association was confounded by an unobserved third variable (such as genetic similarities between children and parents), then we would have expected a weaker relationship between unnatural (and unexpected) causes of child death and parental health. Instead, our findings point to the adverse health impacts of child death regardless of their cause.

The findings from this study may have specific significance for physicians and healthcare workers, suggesting that they need to acknowledge broader collateral health effects when dealing with end-of-life care. Although most discussions on this concern focus on the effects of the death of a parent on surviving children, our findings suggest that the death of a child-including 'children' who have reached adulthood-can have deleterious effects on surviving parents.

A collective perspective in the healthcare system should to a greater extent acknowledge the reactions and experiences of family members and relatives in end-of-life care. A caring and emotional attitude displayed by healthcare professionals has, for instance, been shown to have a positive effect on short-term and long-term parental bereavement. ${ }^{36}$ Furthermore, it seems important that the healthcare system provides psychological support for parents during end-of-life care as well as immediately after the death of a child. ${ }^{37}$ Our findings also conform to the view that it is important for healthcare workers to follow parents who have lost a child over time, ${ }^{38}$ especially since the results suggest longer term consequences of child deaths. Yet, more research is needed on how to support parents following the loss of a child. Finally, the cost-effectiveness assessment of medical interventions in the healthcare system might also alter substantially if benefits and costs incorporate the collateral health effects including interpersonal health consequences following the death of a child. ${ }^{39}$

Some limitations of the register-based data should be noted. Detailed information on personal and relational characteristics is required to uncover the actual causal mechanisms that link child mortality risk to parental death. Ideally, one would like to have access to biological and genetic data, detailed information on diseases from medical records and more information on shared social environment, health behaviours and psychological states. Another shortcoming is the lack of indicators on the quality of the parent-child relationship, which might relate to the risk for adverse health outcomes in bereaved parents. An especially important task for future research is to test the relative importance of underlying mechanisms linking child deaths and mortality in bereaved parents, such as higher parental depression rates, deterioration of health behaviours and onset of acute psychophysiological stress mechanisms. However, testing such mechanisms requires data materials with detailed longitudinal 


\section{What is already known on this subject}

- The death of a child before their parents is considered one of the most stressful and traumatic life events a person may encounter.

- Previous research has chiefly examined parental health effects caused by the loss of a minor child.

- An important threat to causal inference is the possibility that both the death of a child as well as the subsequent ill health of the parent share a common prior cause.

\section{What this study adds}

- Our findings corroborate and extend earlier findings suggesting elevated mortality risks also following the death of an adult child.

- No substantial differences between the impacts of natural versus unnatural child deaths were found which strengthen the possibility that the association between child death and parental health is causal.

- Our findings suggest that healthcare workers need to acknowledge broader collateral health effects when dealing with end-of-life care.

information on bereaved parents. Our restriction of the data to people born in Sweden, who also had parents born in Sweden, also limits our possibility to draw conclusions about the immigrant population residing in Sweden. Effects by the loss of a child may differ among foreign-born people due to, for instance, cultural differences in coping behaviour.

Although the mortality patterns for natural and unnatural deaths were similar, there are still some caveats for inferring causality. Parents and children often resemble each other with respect to personal traits (eg, ability for self-care) associated with mortality and such traits could influence the risk of death from both natural and unnatural causes. They might also share a similar genetic or biological predisposition to lethal diseases. Other common exposures, which may continue to influence health in adult life of both parents and their children, relate to health behaviours. Consequently, some unobserved factors, rather than bereavement per se, may still each one separately influence parental mortality regardless of the cause. On the other hand, the long-term effect of a child's death might also be caused by changes in parental lifestyle factors due to grieving and coping. If so, the changed lifestyles are on the causal pathway and should not be adjusted for. ${ }^{2}$ Future research could study death from specific causes both among children and their bereaved parents in order to add evidence for whether the effects of bereavement are causative.

In summary, our results corroborate and extend the findings from an earlier study suggesting higher mortality risks also following the death of an adult child. ${ }^{2}$ Although our study is unable to furnish the mechanisms of this association, it would seem to merit further investigation as another instance of the linkage of health status across generations.

Funding This work was supported by the Swedish Council for Working Life and Social Research (grant number 2009-0547) and the Swedish Research Council (grant number 2008-1677).

\section{Competing interests None.}

Ethics approval The data used in this study was approved by the Regional Ethical Review board of Karolinska Institutet in 2002-11-11 (decision no. 02-481).

Contributors MR and JS planned the study and the research design. They also analysed data, interpreted the results and wrote the draft version of the paper. IK contributed to writing, interpretation of data and critical reviews. All authors corrected and approved the final version of the manuscript.

Provenance and peer review Commissioned; internally peer reviewed.

\section{REFERENCES}

1. James $\mathbf{L}$, Johnson $B$. The need of parents of pediatric oncology patients during the palliative care phase. J Paediatr Oncol Nurs 1997;14:83-95.

2. Li J, Precht DH, Mortensen PB, et al. Mortality in parents after death of a child in Denmark: a nationwide follow-up study. Lancet 2002;361:363-7.

3. Sanders CM. A comparison of adult bereavement in the death of a spouse, child, and parent. Omega 1979:10:303-22.

4. Middleton W, Raphael B, Burnett $P$, et al. A longitudinal study comparing bereavement phenomena in recently bereaved spouses, adult children and parents. Aust N Z J of Psychiatry 1998;32:235-24.

5. Sirki K, Saarinen-Pihkala UM, Hovi L. Coping of parents and siblings with the death of a child with cancer: death after terminal care compared with death during active anticancer therapy. Acta Paediatr 2000;89:717-21.

6. McEwen BS. Protective and damaging effects of the stress mediators. $N$ Eng/ J Med 1998:338:171-9.

7. Eshtehardi P, Koestner SC, Adorjan P, et al. Transient apical ballooning syndrome-clinical characteristics, ballooning pattern, and long-term follow-up in a Swiss population. Int J Cardiol 2009;135:370-5.

8. Cohen S, Kessler R, Gorden U. Strategies for measuring stress in studies of psychiatric and physical disorders. In: Cohen S, Kessler R, Gorden U, eds. Measuring Stress. New York: Oxford University Press, 1995:3-26.

9. Hendrickson KC. Morbidity, mortality, and parental grief: a review of the literature on the relationship between the death of a child and the subsequent health of parents. Palliat Support Care 2009;7:109-19.

10. Kreicbergs U, Valdimarsdottir U, Onelov E, et al. Anxiety and depression in parents 4-9 years after the loss of a child owing to malignancy: a population-based follow-up. Psychol Med 2004;34:1431-41.

11. Li J, Johansen C, Olsen J. Cancer survival in parents who lost a child: a nationwide study in Denmark. Br J Cancer 2003;88:1698-701.

12. Li J, Hansen D, Mortensen PB, et al. Myocardial infarction in parents who lost a child: a nationwide cohort study in Denmark. Circulation 2002;106:1634-9.

13. Murphy SA, Lohan J, Braun T, et al. Parents' health, health care utilization, and health behaviours following violent deaths of their 12- to 28-year-old children: a prospective longitudinal analysis. Death Stud 1999;23:589-616.

14. Olsen J, Li J, Precht DH. Hospitalization because of diabetes and bereavement: a national cohort study of parents who lost a child. Diabet Med 2005;22:1338-42.

15. Oin P, Mortensen PB. The impact of parental status on the risk of completed suicide. Arch Gen Psychiatry 2003;60:797-802.

16. Birenbaum LK, Stewart BJ, Philips DS. Health status of bereaved parents. Nurs Res 1996:45:105-9.

17. Kvikstad A, Vatten LJ. Risk and prognosis of cancer in middle-aged women who have experienced the death of a child. Int J Cancer 1996;67:165-9.

18. Li J, Johansen SP, Olsen J. Stroke in parents who lost a child. A nationwide follow up study in Denmark. Neuroepidemiology 2003;22:211-16.

19. Rubin SS. The Death of a Child is Forever: The Life Course Impact of Child Loss. New York: Cambridge University Press, 1993.

20. Hasui C, Kitamura T. Aggression and guilt during mourning by parents who lost an infant. Bull Menninger Clin 2004;68:245-59.

21. Arnold J, Gemma PB, Cushman LF. Exploring parental grief: combining quantitative and qualitative measures. Arch Psychiatr Nurs 2005;19:245-55.

22. Dyregrov A, Matthiesen SB. Parental grief following the death of an infant-a follow-up over one year. Scand J Psychol 1991;32:193-207.

23. Martinson IM, Davies B, McClowry S. Parental depression following the death of a child. Death Stud 1991;15:259-67.

24. Vance JC, Najman JM, Thearle MJ, et al. Psychological changes in parents eight months after the loss of an infant from stillbirth, neonatal death, or sudden infant death syndrome-a longitudinal study. Pediatrics 1995;95:933-8.

25. Levav I, Friedlander $Y$, Kark JD, et al. An epidemiologic study of mortality among bereaved parents. N Engl J Med 1988;319:457-61.

26. Levav I, Kohn R, Iscovish J, et al. Cancer incidence and survival following bereavement. Am J Public Health 2000;90:1601-7.

27. Rubin SS, Malkinson R. Parental response to child loss across the life course: clinica and research perspectives. In: Stroebe MS, Hansson RO, Stroebe W, eds. Handbook of Bereavement Research: Consequences, Coping, and Care. Washington: American Psychological Association, 2001:219-39.

28. Fletcher PN. Experiences in family bereavement. Fam Community Health 2002;25:57-70.

29. Merlevede E, Spooren D, Henderick H, et al. Perceptions, needs and mourning reactions of bereaved relatives confronted with a sudden unexpected death Resuscitation 2004;61:341-8.

30. Parkes CM. Bereavement in adult life. BMJ 1998;316:856-9. 
31. Rossi AS, Rossi PH. Of human Bonding: Parent-Child Relations Across the Life Course. New York: Aldine de Gruyter, 1990.

32. Umberson D, Chen M. Effects of a parent's death on adult children: relationship salience and reaction to loss. Am Socio Rev 1994;59:152-68.

33. Marks NF, Jun H, Song J. Death of parents and adult psychological and physical well being: a prospective U.S. national survey. J Fam Issues 2007;28:1611-38.

34. Bowlby J. Attachment and Loss. Vol. 1. London: Hogarth, 1970.

35. Fang $\mathbf{F}, Y$ Y W, Fall $\mathrm{K}$, et al. Loss of a child and the risk of Amyotrophic lateral sclerosis. Am J Epidemiol 2008:167:203-10.
36. Meert K, Thurston C, Celia S, et al. Parental coping and bereavement outcome after the death of a child in the pediatric intensive care unit. Pediatr Crit Care Med 2001:2:324-8

37. Lobb EA, Kristjanson LJ, Aoun SM, et al. Predictors of complicated grief: a systematic review of empirical studies. Death Stud 2010;34:673-98.

38. Milberg A, Olsson EC, Jakobsson $\mathrm{M}$, et al. Family members' perceived needs for bereavement follow-up. J Pain Symptom Manage 2008:1:58-69.

39. Christakis NA. Social networks and collateral health effects. BMJ 2004;24:184-5. 